\title{
What should educational institutions be for?
}

\section{James MacAllister, The University of Edinburgh}

In this article I respond to the work of Gert Biesta regarding the question of what education should be for. He maintains education ought to be oriented towards the 'good' rather than measurement, accountability and efficiency. While sympathetic to such claims, I nonetheless question his avowal that discussion of the purposes of education 'needs' to entail reflection upon tripartite processes of qualification, socialization and subjectification. I also argue that the concept of subjectification presented by Biesta is elusive. He says educators cannot plan to produce it in students. He also suggests there is an unhelpful surplus of reason in education that constrains possibilities for subjectification. According to Biesta, education partly reproduces 'rational communities' that stifle the emergence of human uniqueness and inhibit persons from challenging accepted social orders. In response to this, I argue there is currently a deficit rather than a surplus of reason in education concerning the common good. Following Maclntyre, I claim that educational institutions should support students to learn how to think for themselves and act for the common good. I conclude that such utopian thinking about the purposes of education may be needed, now, more than ever.

\section{Education in an age of measurement}

Gert Biesta (2009 \& 2010) claims we live in an age of educational measurement. In this world education has become ever more centred around and driven by the measurement and comparison of student performance in high stakes assessments at local, national and international levels. He posits that a 'common sense' view of education is responsible for giving so much credence to international programmes of assessment like the Programme for International Student Assessment (PISA) and the Trends in International Mathematics and Science Study (TIMMS). In the common sense (or qualification) view of education, academic achievement in a limited number of subjects like mathematics, language and science is most highly valued. However Biesta (2009) thinks the common sense view of education is flawed - education should be about more than just socialising students and helping them attain qualifications. Biesta implies that it is not just students who suffer in our era of educational measurement. There are increasing expectations that those engaged in educational research will generate evidence about what works, while teachers also now face working in conditions of excessive 'managerial accountability' that have eroded opportunity for responsible professional action (2010 \& 2015).

Biesta thus argues that the emergence of a culture of measurement is problematic as it focuses the educational attention of students, parents, teachers and educational researchers on technical and instrumental values geared towards effectiveness rather than ultimate and normative values. $\mathrm{He}$ is 
not alone is voicing such concerns. For example, Ball (2003) maintains that in more recent times three technologies of educational reform (the market, managerialism and especially performativity) have contributed to significant alterations in educational institutions. At the centre of a performative view of teaching is an ever-expanding database of information about teacher, pupil, school and national school system performance (Ball, 2003). A database of information against which teachers and schools are held accountable for and whose performance they are measured against (Ball, 2003, Munday 2011). A regrettable consequence of the heightened focus on educational measurement is that teachers and schools are increasingly spending more time compiling information that 'proves' they are meeting policy targets or performing better than the 'normal' standards (Ball 2003). Significantly, it is not important that the data schools generate is actually true, only that it shows schools in a positive light and as effective (Ball, 2003). Teachers across the globe are thus increasingly working within an audit culture of international assessment and with a 'horse race mentality' (Kamens, 2013, p 117) where they are encouraged to think most about effective student performance in important exams. This shift in emphasis towards teaching and learning as effective performance inevitably means teachers and schools have less time to actually teach pupils on their own terms (Ball, 2003).

\section{The question of purpose in education}

Biesta argues that the more recent emphasis on assessment, measurement and accountability in education shuts down possibilities for wider thought and debate about the purposes of education $(2009,2010)$. He maintains that in the past twenty years or so a much greater focus has been placed upon the promotion of learning in education policy and practice rather than on education. He claims there are at least two problems associated with this rise in the language of learning (Biesta, 2009). First, while learning is an individualistic concept and generally refers to what a person can do alone (and on what is assessable), education is not something we can do alone - it instead requires relationships between persons (Biesta, 2009, 2010 \& 2015). Second, learning is a term that does not require evaluation of the worthwhileness or otherwise of what is to be learned, or for that matter assessed. Biesta suggests that the new focus on student learning has been accompanied by an ever-greater assessment of student learning. However, the student learning that is most readily assessable may well not be that learning which is most educationally valuable (Biesta, 2009, 2010). Here 'the danger is that we end up valuing what is measured, rather than that we engage in measurement of what we value' (2010, p 26).

Biesta explains that when it comes to education (as opposed to learning): it 'matters what pupils and students learn and what they learn it for' (2009, $p$ 39). Biesta's plea for more discussion about the purposes of education thus seems to be a call for greater debate about the particular content of education allied to enhanced understanding of the reasons and motivations that persons have for engaging in education. However, Biesta seems reluctant to become bogged down in discussion of the particular things that students should learn 
and for what reasons. Indeed, he maintains that he does not want to specify what he thinks the purposes of education should be (Biesta, 2009, 2010, 2012). He rather sets himself the more 'modest' task of raising awareness of some of the functions that education systems actually do serve in the hope this will lead to further and richer debate about the aims and purposes of education. In this respect he argues that education systems perform three main functions: qualification, socialisation and subjectification.

\section{Biesta on what education is for}

Biesta explains that the qualification function of education provides young persons with the knowledge, habits, skills and understanding to do something in the world after their formal education has been completed. Qualification is particularly linked with the contribution education can make to economic growth via the training of a future workforce. However, it is also more than mere certification or preparation for the world of work - it contributes to the development of political and cultural literacy in young persons (Biesta, 2009, 2010). In this respect the qualification function partly resembles the socialisation function of education which: 'inserts individuals into existing ways of doing and being and, through this, plays an important role in the continuation of culture and tradition - both with regard to its desirable and its undesirable aspects' (Biesta, 2009, p 40). Biesta explains that socialisation may be both intentional (through the active transmission of community knowledge, norms and values), or a less intentional effect of education systems as in the case of the hidden curriculum.

He argues that the subjectification function is in many respects the 'opposite of the socialisation function. It is precisely not about the insertion of 'newcomers' into existing orders, but about ways of being that hint at independence from such orders; ways of being in which the individual is not simply a 'specimen' of a more encompassing order (2009, p 40)'. Biesta states that there can be little doubt that education systems do perform the functions of socialisation and qualification. However, he is less confident that education systems always perform the function of subjectification, remarking that for some 'the actual influence of education can be confined to qualification and socialisation' (2009, p 40). Biesta however is willing to put his head above the parapet a little here regarding what education should be for, arguing that any education worthy of the name should also always contribute to subjectification (2010, p 75) and to activities that 'allow those being educated to become more autonomous and independent in their thinking and acting' (2009, p 41). Thus for Biesta, education should ideally entail a balance of qualification, socialisation and subjectification but it is perhaps too often actually only for qualification and socialisation.

What should be made of these 'functions' and their capacity to generate debate about the purposes of education? They do probably have capacity to raise awareness of the increased prevalence of formal assessment and measurement within many education systems. Here I am sympathetic to 
Biesta's point that many education systems currently over do and over value student assessment and teacher and school accountability for the results of such assessments. In this respect he argues that the prevailing tendency within society is to most highly value 'academic' qualifications, pointing out that this regrettably serves to reproduce inequality in society (Biesta, 2009 \& 2010). Those students who attain the highest qualifications in school and/or university are after all more likely to be able to access higher paid jobs in the future than students who have fewer distinctively 'academic' qualifications (Nunn et al 2007). Biesta's doubt that education systems do in fact promote subjectification also reveals how many education systems may be too qualification and socialisation orientated, perhaps especially towards the end of formal schooling when so much attention is given to pupil performance in high stakes assessments. Biesta is probably right then to suggest that awareness of the some of the key functions of education might lead to more informed discussions about what education should be for.

However, in taking what is the case in education as the starting point for debate about the purposes of education, I think Biesta might be inadvertently limiting imaginative thought about what education systems could or indeed should set out to achieve. Indeed, as I shall now argue, there are at least three difficulties with Biesta's framework for considering the purposes of education. Firstly, it is overly prescriptive. This has the unfortunate effect of marginalising traditions of educational thought that do not conform to his system. Secondly, it does not consider in sufficient detail the variety of ways in which the pursuit of knowledge may be educational. Thirdly, the concept of subjectification presented by Biesta is rather elusive. He claims that educators cannot plan to produce it in students. He also seems to suggest that there is a damaging surplus of reason in education that stultifies the goal of subjectification. In response to this, in the final sections of the paper I argue that there is currently a deficit rather than a surplus of reason in education concerning the common good. Following Maclntyre, I claim that educational institutions should support students to learn how to think for themselves and act for the common good.

\section{Biesta on good education}

'In order to bring issues of value and purpose back into our discussions about education, particularly in situations in which measurement figures prominently, we therefore need to reengage with the question as to what constitutes good education' (Biesta, 2010, p 14)

Biesta's framework for promoting discussion about the purposes of education is very prescriptive in at least two ways. On the one hand Biesta seems to assume that considering the question of what education is for, is essentially a matter of thinking about what constitutes a 'good' education. On the other hand, he also states that determining what counts as a good education ultimately amounts to deciding which particular combination of socialisation, qualification and subjectification is most appealing and warrantable. 
Regarding the former, he implies there is no reason to question the purposes of education from a blank slate. Instead there is a particular 'need' to reconnect with the question of what constitutes a 'good' education in situations where measurement agendas dominate (2010). Quite why discussion about the purposes of education is collapsed down into what constitutes good education is not clearly explained. This strikes me as a rather perplexing and reductive way of trying to open up debate about the purposes of education. I do accept Biesta's implication that a good education is not synonymous with an effective one. However, contrary to Biesta, I do not think it is necessary to focus on the issue of what constitutes 'good' education in order to overcome the view that effectiveness is all education should be for.

Moreover, while Biesta (2010) acknowledges that a wide range of views about the purposes of education already exists, he nonetheless insinuates that it not possible to consider the purposes of education without reference to his threefold framework. He says that 'when we engage in discussions about what education should be for, we should do so in relation to these three dimensions...in reality there will always be a particular "mix" of the three purposes of education, which means that the real question is not whether we should opt for qualification, socialisation or subjectification but what particular combination we see as desirable and justifiable' (Biesta, 2010, p 5). In this short passage Biesta appears to be arguing that persons wanting to consider the purposes of education not only should - they ultimately must, do so in reference to his threefold framework'. Contrary to Biesta however, I do not see why reflection on the purposes of education needs must entail reflection upon tripartite processes of socialisation, subjectification and qualification. Indeed, insistence that consideration of the ends of education amounts to no more than deciding which combination of socialisation, qualification and subjectification is desirable arguably marginalises traditions of educational thought that would not frame debate about the ends of education in such ways. There is of course a rich variety of literature concerning the purposes of education (see for example Whitehead, 1967; Hirst, 1968; Peters, 1981; Winch, 1996; Carr, 2000; White, 2007; Dewey, 2008 and Macmurray 2012) that is not framed around issues of socialization, subjectification and qualification.

Pertinent to the context of this discussion is Peters claim, in Essays on Educators, that though the aims of education may be contestable, they are not completely so. That the aims of education may not be completely contestable does not mean that they need to be contested within the framework that Biesta proposes. Indeed, Peters shows that it is possible to construct a well thought out account of the aims of education without any need to discuss which combination of qualification, socialisation and subjectification is most desirable. Though Peters is perhaps best known for his argument that education should initiate students into worthwhile forms of 
knowledge (1970) in Essays on Educators he concedes that 'though this is an aim of education, it is surely a very narrow one' (1981, p 35). Peters therefore set out a range of other possible aims of education including self-fulfilment, a concern for truth and others, emotional and moral development, preparation for working life as well as the fostering of democratic values. Here Peters stresses that democracy requires widespread participation in public life as well as rational questioning and discussion of public policy (1981, p 37). However, as we shall go on to see, Biesta (unlike Peters and Maclntyre) suggests that communities today might be too rational, to their detriment.

A second problem with Biesta's scheme is the pragmatist conception of knowledge that underpins it. He avers that the qualification function of education is especially concerned with (curriculum) content and indicates that he does not want to 'downplay the importance of content in schooling' (2010, $\mathrm{p}$ 104). In one sense curriculum content is valuable for pragmatic reasons of qualification - pragmatic as qualifications can help persons go on to do other things in later life. However, Biesta provides an articulate defense of other ways in which pragmatic knowledge is valuable elsewhere (2014). Drawing upon Dewey he maintains that pragmatic knowledge is intimately linked to reflection upon action and especially the solving of problems. Curriculum content might be especially valuable (from a pragmatist standpoint) when it helps persons build up knowledge on the basis of their experience and with an eye on future possibilities rather than past certainties.

One would hope that students in educational institutions would build up knowledge at times with reference to their experiences and problems and with an eye on future possibilities. The implication, however, that curriculum knowledge will generally be concerned with the 'certain' and the 'true' unless it is underpinned by a pragmatist philosophy, rings a little false. Indeed I think most educators do not need to seek recourse to pragmatism in order to grasp that curriculum knowledge is generally a matter of probability and possibility rather than certainty. Perhaps a bigger issue with the pragmatist conception of knowledge adopted by Biesta is that it does not consider in sufficient detail the variety of ways in which the pursuit of knowledge may be educational above and beyond the pragmatic. The idea that students might benefit from pursuing knowledge for its own sake does not really figure in Biesta's framework for example.

In fairness to Biesta, he does suggest that curriculum knowledge may be significant for reasons other than pragmatic or instrumental ones. It may also provide opportunities for subjectification. Biesta maintains that some will feel excluded from particular curricula - as curricula are always only a selection of what might be possible (2010, p 105). While 'making abstract knowledge one's own knowledge is not relevant' to subjectification (2010, p 106), if 
knowledge content is 'taken seriously' it may provide a starting point for new entrances into the world, for new possibilities. However, the particular ways in which curriculum knowledge may enable subjectification are far from clear. Biesta seems reluctant to discuss the specific bodies of knowledge that might be most worthwhile for young persons to 'take seriously'. The concept of subjectification that Biesta presents readers with is, to my mind, rather elusive. This may be partly put down to issues of translation. Indeed, Biesta (2012) has acknowledged that the concept of subjectification may be difficult to comprehend in the English language. However, just because something may appear elusive does not mean that it should be dismissed - and Biesta does have something important to say regarding subjectification.

\section{The universal 'Good' and Education for Subjectification}

Biesta maintains that Immanuel Kant is a key figure in the history of the idea of educating for subjectification (2010). He argues that it was only after Kant that it became possible to distinguish between education as mere socialization (educating to insert newcomers into existing social orders) and education that involves aspects of subjectification (educating for human freedom from existing social orders). Kant famously argued that education should first involve a disciplined socialization into societies rules prior to the more important ultimate goal of fostering rational autonomy in persons (2003). Kant thought education should aim at the universal good because the universal good is humanities destinyii. Education is universally good, for Kant, when it enables all persons to reason for themselves. He stated that it is through good education that all the good in the world arises' (Kant, 2003, p 15). This utterance may represent a clue as to why Biesta thinks discussions about the value and purpose of education need to focus on what constitutes good education. Biesta certainly appears to have been influenced by Kant's idea that good education is needed for all. He recently remarked that 'the duty of education is to ensure that there is good education for everyone everywhere' (Biesta, 2015, p 81).

However, unlike Kant, Biesta doubts whether there is a 'universal' human good determinable in advance that it is the task of education to promote. Indeed, Biesta specifically wants to question the Kantian view that attaining the capacity for independent thought and rational freedom constitutes the only or proper 'good' of education. He remarks that with 'Kant autonomy based upon the use of reason became the marker of humanity - which left those who were considered to be not or not yet rational, including children, in a "difficult" position' (Biesta, 2010, p 77). What is wrong with the reason-based humanism of Kant is that is it not open to the possibility that newcomers might alter what it means to be human. Indeed, Biesta implies that the Kantian account of human subjectivity needs to be replaced by a more open and less 
reason orientated account of human subjectivity. Biesta does still think education should aim to inculcate student subjectication, just subjectification of a different sort. Two concepts are central to Biesta's account of education for subjectification: coming into the world and uniqueness (2010, $p$ 81). Biesta draws upon Hannah Arendt to explain the former idea.

For Arendt we live in a world populated by others who are unlike us. In order to come into such a world of diverse persons, action is necessary. Acting entails doing something new, something that has not been done before. However, Biesta explains that it is always possible that other persons may take up such 'new' actions and beginnings in unpredicted ways. Thus, there is a two-fold sense to human subjectivity for both Biesta and Arendt. Subjects both initiate new actions and are also subjected to the consequences of their actions. Here the uniqueness of each person becomes significant: it is because the world is made up of persons who are different from each other that the consequences of new actions are not predictable. Biesta explicitly states his preference for this two-fold interpretation of human subjectification (2010, p 83). Unlike Kant's account of human subjectivity, coming into the world as a subject is only possible when it is accepted that all persons are in some way unique and not knowable in advance on account of their capacity for rational autonomy.

Biesta develops the idea of educating for human uniqueness further with reference to the work of Levinas and especially Lingis (1994). According to Biesta, what matters to Levinas and Lingis is not so much that persons are uniquely different from others, but that they are irreplaceably unique (2010). Here Biesta draws upon Lingis to suggest that 'rational communities' may be closed off to the voices and actions of those deemed different. Moreover, Biesta claims that education plays a key part in reproducing such 'rational communities'. While Biesta and Lingis both stress that rational communities are not without value, they nonetheless feel that rational communities are not open to 'uncommon' views. Instead rational communities only permit 'representative' voices to be heard. Biesta explains this like so:

'We expect from Doctors, electricians, airline pilots and so on that they speak according to the rules and principles of the rational discourse of the community of which they are a representative. This means, however, that the thing that matters when they speak is what is said... who is saying it is immaterial as long as what is said (and done) "makes sense"...when we speak in this capacity we do not speak with our own voice but with the common voice of the community we represent...we 
are, therefore, interchangeable...our uniqueness does not count and is not at stake' (Biesta, 2010, p 87)

However, Biesta thinks human uniqueness should be at stake in education. $\mathrm{He}$ argues that if the world is divided up into a series of rational communities, newcomers will not be able to speak in their own voices. Newcomers will not, he suggests, be able to interrupt the 'normal' order. Counter to this Biesta argues that pedagogies must aim to keen open the possibility for newcomers to interrupt the 'normal' rational orders (2010, p 91). However, educators looking for guidance about how to help students 'speak in their own voices' will be disappointed. Biesta avers that educators cannot set out to 'produce' the emergence of such student uniqueness (2010). He states that it is only when we give up the idea that human subjectivity can in some way be educationally produced that spaces might open up for uniqueness to come in to the world' (2010, p 91). Biesta seems to here suggest there is an unhelpful surplus of reason in education that constrains possibilities for subjectification. Rational communities stifle the emergence of human uniqueness and inhibit persons from challenging accepted social orders.

\section{Maclntyre on the purposes of education}

Biesta (2010) thinks that the current preoccupation with measurement in education tends to encourage individuals to think about what they (or their offspring) can get out of education, instead of any shared consideration of the common public good. He argues that in the past public institutions did afford space through which private concerns could become public ones. However, he suggests that in contemporary life the public sphere has receded to such an extent that any 'robust belief in the idea of the common good' (2010, $p$ 103) has been lost. This is a theme developed by Alasdair Maclntyre. Maclntyre maintains that the prevailing values in public institutions in advanced modernity militate against students being able to learn to think about the common good (1987 \& in debate with Dunne 2002). However, Maclntyre suggests that the reduction in opportunity for public debate about the common good is due to a lack of reason in public institutions rather than a surplus of it. Maclntyre implies that the rhetoric (rather than the reason) of the powerful in capitalist societies will continue to prevail in matters concerning the common good until there is an educated public able to hold the powerful to account. Though Macintyre concedes that the rhetoric of the powerful tends to prevail in advanced capitalist societies, he does not advocate that teachers give up on the task of trying to encourage students to reason about matters concerning the public good ${ }^{\text {iii. }}$.

Indeed, in his lecture on The Idea of An Educated Public Maclntyre argues that western educators have two key purposes. They need to both 1) prepare students for a future social role, while also 2) supporting them to become able to think for themselves. He says that the first purpose of educators 'is among 
the purposes of almost all education almost everywhere: it is to shape the young person so that he or she may fit into some social role or function... The second purpose is...the purpose of teaching young persons to think for themselves' (1987, p 16). On the face of it, Maclntyre seems to be defending precisely the sort of Kantian view of education (aimed at promoting rational autonomy in students) that Biesta seeks to call into question. However, while Maclntyre cites Kant in his lecture on the educated public, he is not a Kantian thinker. In his well-known book After Virtue, he argued that the Kantian Enlightenment project was doomed to fail because the idea that it is possible to rationally determine the universal human good does not take into account that different communities have diverse, at times incompatible, ideas about the human good. However, Maclntyre revises rather than gives up on the idea that educators should help students' thinks for themselves about what it might be good for them to do in their lives.

\section{Thinking for oneself}

The first thing to note about Maclntyre's defence of the idea that educators ought to encourage students to think for themselves is that he regards this as a necessarily communal process. He states that 'it is a familiar truth that one can only think for oneself if one does not think by oneself' (1987, p 24). Macintyre seems to suggest there are at least two ways in which persons can so learn to think for themselves. On the one hand persons can learn to think for themselves via rational debate with others about matters concerning the common public good (Maclntyre 1987, 1990 \& 2002 with Dunne). Maclntyre argues that a vital aspect of thinking for one self entails asking questions of currently dominant social and economic orders (Maclntyre 2002 with Dunne). For educators in Western culture this may mean supporting students to ask questions about why society is so geared toward the accumulation of individual wealth and the growth of a market economy rather than on the more even distribution of wealth for the overall common good. It may also mean encouraging students to ask questions about the massive debt burden being thrust upon an unprecedented number of persons today (Maclntyre 2013). Thus thinking for oneself should not be confused with thinking of oneself. The person that thinks of themself merely uses reason to accumulate goods for themselves. The person who thinks for themselves is not so self orientated. They are committed to asking questions about unjust social orders, and they are concerned with the pursuit of the common good as well as their own.

On the other hand persons can learn to think for themselves by reading and then debating canonical texts. Maclntyre argues that close reading and debating of texts in university seminars can help provide persons with shared frames of reference that can inform debate about the common good. For if debate about the common good is to be based on reason rather than rhetoric 
then shared frames of reference and standards of appeal by which arguments can be judged as better or worse are needed (Maclntyre 2002 with Dunne). However, to be committed to rational debate about issues concerning the public good is not to be blind or indifferent to the reality of human diversity. Indeed, for Maclntyre it is often through engagement with texts from different traditions and persons from other cultures and backgrounds that we learn most. In this respect, though Maclntyre has been accused (see Harris, 2012) of adopting a view of community that is not open to the uncommon, I am inclined to disagree. After all, he specifies that debates in educated publics are open to the introduction of new discoveries, possibilities and points of view (Maclntyre \& Dunne 2002). While certain discourses may sometimes prevent uncommon voices from being heard in public, for Maclntyre it is ultimately prejudice and rhetoric rather than reason than leads to such indifference to difference. ${ }^{\text {iv }}$

\section{The input-output model of education}

Maclntyre's philosophy of education is also a partly liberal one. He says that towards the end of formal education, educators need to be able to help students pursue practices like historical, scientific or literary inquiry for their own sake rather than for later reward. He states that 'part of what such students need to learn is to value, for example, the activities and outcomes of scientific enquiry for their own sake and not just for the technologies that result from such enquiry. Students who ask about their academic disciplines 'But what use are they to us after we leave school?' should be taught that the mark of someone who is ready to leave school is that they no longer ask that question' (Maclntyre with Dunne, 2002, p 5). Unlike Biesta, Maclntyre is clear then that the pursuit of different bodies of knowledge ought to be regarded as worthwhile in and of itself, at least at times, in educational institutions. However, like Biesta, MacIntyre is sceptical of only valuing educational institutions according to their efficiency and productivity and their capacity to support students to attain high grades in important examinations. Maclntyre dubs a fixation with measurement and student examination as an input/output model of education.

What is 'wrong with this model is that it loses sight of the end of education, the development of its students' powers, and substitutes for this end that of success by the standard of some test or examination. Yet what examinations principally test is how good one is at passing examinations' (Maclntyre with Dunne, 2002, p 4). Instead of adopting the input-output model, Maclntyre suggests educational institutions should focus on extending the power of students' to both think for themselves and act for the common good (MacAllister, 2015). There are similarities then between the views of Biesta and Maclntyre. Both think there is a too much measurement in education. Both also think educational institutions need to provide spaces for students to 
interrupt dominant social orders. However, there are also important differences of opinion. Whereas Biesta seems to think 'communities' are often too rational, Maclntyre thinks they are not rational enough. However, contrary to Barr's allegation (2008), Maclntyre does not hold the view that only rational argument can improve the conditions of human community. ${ }^{v}$

\section{Practical reason and education for the common good}

'Practical rationality is a property of individuals-in-their-social relationships rather than of individuals-as-such...Our primary shared and common good is found in that activity of communal learning through which we together become able to order goods...Such practical learning is a kind of learning that takes place in and through activity, and in and through reflection upon that activity, in the course of both communal and individual deliberation' (Maclntyre, 1998, pp 242-243)

While Maclntyre thinks debating canonical texts and issues concerning the public good are ways in which persons can learn to reason about the common good, he does not think these are the only ways in which the common good may be worked towards. Indeed, in Politics, Philosophy and the Common Good, Maclntyre suggests that the primary common good of human persons entails collective acts of practical learning. He holds that through practical activity with others, each person can learn what it is good for them to do in their life. According to Maclntyre, working out what is good for a person to do in their life is a matter of practical reason - and each person can only learn do this with others. He argues that taking part in co-operative practices (he gives fishing, farming, playing in an orchestra and being part of a team of scientists as examples) can afford opportunities for persons to think with others about what it is good for them to do in their lives. He suggests that the person of practical reason has learned how to order the activities of their life in such a way that they are able to think about more than their own immediate desires. Here he says that young persons need to learn which of their desires are for genuine goods and which are not (2013b). Genuine goods enable individual and communal human flourishing. False goods meanwhile merely serve the ends of the current (consumer driven and individualistic) economic order (2013b). Persons of practical reason, he suggests, desire genuine as opposed to false human goods - they have learned how to think for themselves and act for the common good. vi

Here, Maclntyre indicates that the way in which persons are initiated into practices is crucial. If persons are only encouraged to perform the practice in a specialist and compartmentalized way with a focus on their individual desires alone then it will become all too easy for common concerns to get lost. If on the other hand persons are encouraged to consider how their performance of the practice might influence the course of their life and those of others in the longer term then it will be much easier to raise issues 
concerning the public good ${ }^{\text {vii }}$. While the dominant social and economic orders are very good at preventing such practical reason about the common good from emerging Maclntyre does not think educators should give up (2013b). He argues that a 'utopianism of the present' is needed to combat the ideology of advanced capitalism. While utopians of the future sacrifice the present for the future, utopians of the present refuse to sacrifice away the present. Instead, they insist that 'the range of present possibilities is always greater than the established order is able to allow for' (Maclntyre, 2013b, p 17). Maclntyre explains that it is in situations of everyday conflict that utopian questions about the common good really matter.

He argues that what is needed is 'a transformative political imagination, one that opens up opportunities for people to do kinds of things that they hitherto had not believed they were capable of doing. And this can happen when... parents become involved in some community that sustains their children's school' (ibid, p 17). Maclntyre argues that it sometimes becomes possible for people in a community to reflect upon the sort of school they want their children to attend. When this opportunity for participation and decision-making about the purposes of a school emerges the 'achievement of human goods often takes new and unpredicted forms for which the existing social order hitherto afforded no space' (Maclntyre, 2013b, p 17). What Maclntyre is alluding to here is that though many contemporary schools do not provide much in the way of opportunity to help young persons think for themselves and act for the common good, this need not always be the case, especially if persons in communities can come together to question the purposes of their schools. Thus, for Maclntyre, it is possible for educational institutions to become places where collective action can subvert the individualistic ideals of advanced capitalism. This could entail rational debate about the common good or collective practical reasoning about what it may be good for people to do in their lives. It might also entail persons in communities coming together to think about the purposes of schooling.

While I am largely sympathetic then to many of Maclntyre's claims concerning education, they do not all convince. For example, his belief that establishing and maintaining distinct faith schools (such as Protestant, Catholic or Islamic ones) in the same locality might further conditions of tolerance and understanding may be a little paradoxical. For if the best way to overcome prejudice is to encourage people to live together and participate in shared projects as Maclntyre has it, why encourage young persons of different faiths to be educated in separate schools? Even if extensive effort is made to ensure that pupils and teachers from such different schools frequently intermingle (as Maclntyre says they should in conversation with Dunne 2002), if the aim is to learn to live together why not actually live together all the time when at school? Nor does the hope that alternative forms of schooling (driven 
by something other than the needs of the market economy) can spring into existence seem wholly realistic. In the current climate of measurement I personally do not find it easy to imagine many Western educational institutions and systems being able to consistently resist, let alone overcome, the competitive and individualistic social and economic values that increasingly animate Western culture.

It is telling that Maclntyre goes all the way back to the time of the Scottish Enlightenment to provide an example of an education system that actually fulfills his criteria for an educated public. His recent avowal that 'we badly need good empirical studies of both success and failure in creating forms of schooling that enable children, their parents, and their teachers to achieve forms of good not otherwise achievable' ( $p$ 17, 2013b) is probably not just a call for educational research studies of contemporary schools that are driven by something other than the needs of the market economy. It is also perhaps an acknowledgement that if such alternative practices of schooling exist at all, they do so sporadically, where they are as liable to failure as success. However, in fairness to Maclntyre, he defends the need for such utopian thinking about educational institutions on the grounds that it can help shed light on how far away educational institutions often are from where they should be. Utopian thinking can be instructive he seems to be saying even if it is not always realistic. It is also noteworthy that the tone of Maclntyre's later work is more upbeat than what preceded it. His middle period works (such as After Virtue and the Idea of an Educated Public) were rather pessimistic about the prospect of capitalist values being subverted by collective thought and action for the common good. In contrast to this, his later thinking (see especially 1999, 2002 with Dunne and 2013b) does, despite some flaws, stress that educational institutions might yet still become places where persons can learn how to think for themselves and act for the common good.

\section{What should educational institutions be for?}

In this paper I have considered what educational institutions should be for. I have agreed with Biesta on a number of points. It is no doubt important that schools, colleges and universities ease young persons into society by initiating them into prevailing cultural orders and supporting them to obtain qualifications. I am generally in agreement with another of Biesta's main arguments too: that reflection on the purposes of education is needed so as to challenge the culture of over doing and over valuing measurement. Educational institutions should do more than just socialise and qualify. In spite of these sympathies I have also suggested that Biesta's tripartite framework regarding the purpose of education has at least three flaws. For one, it is overly prescriptive. Here I have questioned Biesta's avowal that discussion of the purposes of education needs to entail reflection upon socialisation, 
subjectification and qualification. There is after all a rich variety of literature concerning the purposes of education that is not framed around issues of socialization, subjectification and qualification.

A second problem with the scheme is that it does not consider the variety of ways in which the pursuit of knowledge might be valuable beyond the pragmatic. Maclntyre is much clearer than Biesta about the variety of ways in which the pursuit of knowledge may be educationally valuable. Maclntyre thinks knowledge ought to be pursued for its own sake, at least at times, while Biesta's does not, as far as I am aware. Maclntyre (2009) is also explicit about how pursuing knowledge in a variety of different disciplines might enable students to develop the critical understanding necessary for questioning unjust social and economic arrangements. While Biesta does allude to how subjectification may occur when the content of education is seriously considered, this concept is, by Biesta's own admission, difficult to grasp for English language speakers.

Indeed, the final problem is to do with the elusiveness of the idea of subjectification. Biesta appears to suggest there is an unhelpful surplus of reason in education that constrains the emergence of human uniqueness and inhibits persons from challenging accepted social orders. Contrary to this, I have argued that that there is currently a deficit rather than a surplus of reason in education concerning the public good. In this respect, I have drawn upon Maclntyre to suggest that educational institutions should support students to think for themselves and act for the common good. Maclntyre stresses that we need to think with others in order to think for ourselves. Here educators need to assist students to together acquire, question, debate and remake valued knowledge. Knowledge traditions are not for Maclntyre certain, and their value is not restricted to the individual. Indeed, Macintyre argues that thinking for one self entails questioning dominant social and economic orders, especially when they are unjust. Thinking for oneself is therefore linked to the idea of acting for the common good. Acting for the common good entails striking a balance between pursuing goods for one self and supporting others to get goods. It involves collective acts of practical learning, where each person learns what it might be good for them to do in their life. Acting for the common good may also involve collective action that subverts the individualistic ideals of advanced capitalism.

While there are no doubt similarities between the work of Maclntye and Biesta, there are also important differences. Whereas Biesta seems to think 'communities' are sometimes too rational, Maclntyre thinks they are not rational enough. For Maclntyre it is prejudice and rhetoric (rather than reason) that prevents the voices of the uncommon from being heard. Whereas Biesta suggests educators cannot produce student subjectification, MacIntyre suggests educators should not give up on the idea that they can help young persons to collectively think about what it may be good for them to do in their lives. Biesta and Maclntyre do however seem to agree that ongoing debate about the purposes of education is needed if communities are to be altered for 
the better. ${ }^{\text {viii I }}$ am also inclined to agree. For as Maclntyre suggests, if parents, teachers, school pupils, students, politicians, academics and other persons besides these do together question the purpose of educational institutions it may become possible to interrupt the individualistic ideals that pervade much contemporary public life. Indeed, in this age of measurement, utopian thinking about the purposes of education may be needed, now, more than ever.

\section{Notes}

'However, it should be acknowledged that Biesta is elsewhere more 'modest' about his threefold framework, suggesting that it might be 'one way' (2009), of enabling thought about the purposes of education rather than the only way (2010).

ii For further discussion of Kant's idea that education should foster the universal good, see Kant (2003), chapter 1 especially.

iii For further discussion of this point see MacIntyre and Dunne (2002) and MacAllister (2015).

${ }^{\text {iv }}$ For further discussion of this issue see MacAllister (2015) and Maclntyre and Dunne (2002)

${ }^{\vee}$ For further critical discussion of Maclntyre's philosophy see Horton and Mendus (1994). For discussion of criticisms of Maclntyre's philosophy of education see MacAllister (2015).

${ }^{v i}$ For further discussion of the idea that Maclntyre's philosophy of education entails supporting students to think for themselves and act for the common good see MacAllister (2015)

vii Dunne has of course criticised Maclntyre for not classifying teaching as a practice (Maclntyre and Dunne 2002). However what seems most important for Maclntyre is that practices are performed in educational spaces in such ways that the common good is thought about and worked towards. Whether teaching is considered to be a practice or not is very much a secondary issue.

viii Maclntyre and Biesta are not the only scholars to air such views. Winch for example argues that there is a need for the various people who have a stake in education (including parents, teachers, students and teachers) to engage in serious debate about the purposes of education. However he concludes such debate has yet to happen in the UK despite high profile calls for it. He claims that in the absence of such meaningful debate about the ends education in the UK a dominant liberal tradition 'exercises undue sway over the system as a whole, to its considerable detriment' (1996, $P$ 42). What is needed instead, Winch suggests, is a 'vocational education of a liberal temper' (ibid, $p$ 42).

\section{References}

Ball, S. (2003) The teachers' soul and the terrors of performativity, Journal of Education Policy, 18 (2), 215-228

Barr, J. (2008) The Stranger Within: On the Idea of an Educated Public (Rotterdam, Sense Publishers)

Biesta G (2009) Good education in an age of measurement: on the need to reconnect with the question of purpose in education, Education, Assessment, Evaluation \& Accountability, $21,33-46$

Biesta G (2010) Good education in an age of measurement: Ethics, Politics, Democracy, 
(London, Paradigm)

Biesta G (2012) The future of teacher education: Evidence, competence or wisdom?

Research on Steiner Education, Vol. 3 (1), 8-21

Biesta G (2014) Pragmatising the curriculm: bringing knowledge back in to the curriculum conversation, but via pragmatism, The Curriculum Journal, 25 (1), 29-49

Biesta G (2015) What is education for? On Good Education, Teacher Judgement Educational Professionalism, European Journal of Education, vol. 50 (1), 75-87

Carr D (2000) Professionalism and Ethics in Teaching (London, Routledge)

Dewey, J. (2008) Democracy and Education (Minneapolis, MN, Filiquarian).

Harris, S. (2012) The University's Uncommon Community, Journal of the Philosophy of Education, 46.2, 236-250

Hirst P (1968) Liberal Education and the Nature of Knowledge, in Philosophical Analysis and Education, Routledge \& Kegan Paul, London, pp 113-138

Horton J \& Mendus S (editors) (1994) After Maclntyre: Critical Perspectives on the Work of Alasdair Maclntyre, (Cambridge, Polity Press)

Kamens, D. (2013) Globalization and the emergence of an audit culture: PISA and the search for 'best practices' and magic bullets, in: Heinz-Dieter, Meyer. \& Aaron, Benavot. (2013) PISA, POWER and POLICY: the emergence of global education governance, (United Kingdom: Symposium)

Kant I (2003) On Education, (New York, Dover Publications)

Lingis A (1994) The Community of those who have nothing in common (Indianapolis, Indiana University Press)

MacAllister J (2015) Macintyre's revolutionary Aristotelian philosophy and his Idea of an Educated Public Revisited, Journal of Philosophy of Education, DOI: 10.1111/14679752.12151

Maclntyre A (1984) After Virtue: A Study in Moral Theory, (Indiana: University of Notre Dame)

Maclntyre (1987) The Idea of an Educated Public, in Education and Values: The Richard Peters Lectures, Ed. By Haydon G, (London, The Institute of Education)

Maclntyre A (1990) Three Rival Versions of Moral Inquiry: Encyclopaedia, Geneaology and Tradition, (Indiana: University of Notre Dame)

Maclntyre A (1998) Politics, Philosophy and the Common Good, in The MacIntyre Reader, Ed. by Knight K, (Cambridge, Polity Press)

Maclntyre A \& Dunne J (2002) 'Alasdair MacIntyre on Education: In dialogue with Joseph Dunne', Journal of Philosophy of Education, Vol. 36, No. 1, 1-19

MacIntyre A (2009) The Very Idea of a University: Aristotle, Newman and Us, British Journal of Educational Studies, vol. 57 (4), 347-362 
Maclntyre A (2013) Where we were, where we are, where we need to be, in Virtue and Politics: Alasdair Maclntyre's Revolutionary Aristotelianism, ed. by Blackledge P \& Knight K (Indiana, University of Notre Dame Press)

Maclntyre A (2013b) How Aristotelianism Can Become Revolutionary: Ethics, Resistance and Utopia, in Virtue and Politics: Alasdair Maclntyre's Revolutionary Aristotelianism, ed. by Blackledge P \& Knight K (Indiana, University of Notre Dame Press)

MacMurray, J. (2012) Learning to be Human, Oxford Review of Education, 38 (6), 661-674.

Munday, I. (2011) Derrida, teaching and the context of failure, Oxford Review of Education, $37: 3,403-419$

Nunn, A. et al. (2007) Factors Influencing Social Mobility, (Leeds, Department of Work and Pensions Research Report)

Peters R (1981) Essays on Educators, (London, George Allen \& Unwin)

Peters R (1970) Ethics and Education, (London, George Allen \& Unwin)

White J (2007) What schools are for and why, IMPACT Paper No 14. (Philosophy of Education Society of Great Britain)

Whitehead, A. (1967) The aims of education and other essays. New York: The Free Press.

(First published 1929)

Winch C (1996) Quality and Education, (Cambridge, Blackwell) 